\title{
A Survey of the Pseudomonas syringae pv. tomato DC3000 Type III Secretion System Effector Repertoire Reveals Several Effectors That Are Deleterious When Expressed in Saccharomyces cerevisiae
}

\author{
Kathy R. Munkvold, Michael E. Martin, Philip A. Bronstein, and Alan Collmer \\ Department of Plant Pathology, Cornell University, Ithaca, NY 14853, U.S.A.
}

Submitted 4 October 2007. Accepted 23 December 2007.

\begin{abstract}
The injection of nearly 30 effector proteins by the type III secretion system underlies the ability of Pseudomonas syringae pv. tomato DC3000 to cause disease in tomato and other host plants. The search for effector functions is complicated by redundancy within the repertoire and by plant resistance $(R)$-gene sentinels, which may convert effector virulence activities into a monolithic defense response. On the premise that some effectors target universal eukaryotic processes and that yeast (Saccharomyces cerevisiae) lacks $R$ genes, the DC3000 effector repertoire was expressed in yeast. Of 27 effectors tested, HopAD1, HopAO1, HopD1, HopN1, and HopU1 were found to inhibit growth when expressed from a galactose-inducible GAL1 promoter, and HopAA1-1 and HopAM1 were found to cause cell death. Catalytic site mutations affecting the tyrosine phosphatase activity of HopAO1 and the cysteine protease activity of HopN1 prevented these effectors from inhibiting yeast growth. Expression of HopAA1-1, HopAM1, HopAD1, and HopAO1 impaired respiration in yeast, as indicated by tests with ethanol glycerol selective media. HopAA1-1 colocalized with porin to yeast mitochondria and was shown to cause cell death in yeast and plants in a domain-dependent manner. These results support the use of yeast for the study of plant-pathogen effector repertoires.
\end{abstract}

Additional keywords: hypersensitive response.

Many gram-negative bacterial pathogens utilize a type III secretion system (T3SS) when causing diseases in animal or plant hosts. The T3SS translocates effector proteins into the host cytoplasm, thereby subverting host defenses for the benefit of the pathogen. Understanding the functions of effectors in plant pathogens has been particularly difficult because apparent redundancies in their large effector repertoires mask virulence phenotypes in loss-of-function studies and because plant resistance $(R)$-gene sentinels may convert different effector virulence activities into a monolithic defense response known

Current address of P. A. Bronstein: United States Department of Agriculture-Agricultural Research Service, Robert W. Holey Center of Agriculture and Research, Ithaca, NY 14853, U.S.A.

Corresponding author: A. Collmer; E-mail: arc2@cornell.edu; Telephone: +1.607 .255 .7843 ; Fax: +1.607.255.4471;

* The $\boldsymbol{e}$-Xtra logo stands for "electronic extra" and indicates that four supplemental figures and one supplemental table are published online. as the hypersensitive response (HR) in gain-of-function studies. These problems are exemplified by the model plant pathogen Pseudomonas syringae pv. tomato DC3000, which can cause bacterial speck disease in tomato and the model plants Arabidopsis and Nicotiana benthamiana. The pathogen translocates nearly 30 effector proteins that are collectively essential for virulence into the host cell cytoplasm (Chang et al. 2005; Ferreira et al. 2006; Lindeberg et al. 2006; Schechter et al. 2006; Vinatzer et al. 2005). A current challenge is to systematically determine the virulence functions, biochemical activities, and host targets of these proteins.

Several gain-of-function studies involving effectors individually delivered by nonpathogens expressing a cloned $P$. syringae T3SS or produced from effector transgenes within plant cells have helped define two major biological processes perturbed by approximately half of the DC3000 effectors, namely suppression of the HR, a programmed cell death that is associated with strong resistance specifically in response to pathogens (Abramovitch et al. 2003; Bretz et al. 2003; Espinosa et al. 2003; Jamir et al. 2004; Lopez-Solanilla et al. 2004), and suppression of basal resistance, a more general resistance directed toward any microbe that finds itself within plant tissue (DebRoy et al. 2004; Hauck et al. 2003; He et al. 2006; Li et al. 2005; Oh and Collmer 2005). Gain-of-function analyses have been particularly useful in providing clues to function, because each effector can be assayed individually and the test proteins often are strongly produced, allowing for amplification of subtle effects. In addition, clues based on either protein motifs, structure, or both have led to experimental demonstration of biochemical functions (and in some cases host targets) for several P. syringae effectors (Abramovitch et al. 2006; Axtell et al. 2003; Bretz et al. 2003; Espinosa et al. 2003; Fu et al. 2007; Jelenska et al. 2007; Lopez-Solanilla et al. 2004; Ma et al. 2006b; Rosebrock et al. 2007; Shao et al. 2002; Zhang et al. 2007).

To discover new clues to the functions of effectors, we examined the consequences of induced expression of these proteins on the growth and viability of the yeast Saccharomyces cerevisiae. The premise for screening the repertoire of DC3000 effectors in yeast is that effectors have evolved to perturb a variety of cellular processes in host cells, that some of the associated targets are likely to be universal eukaryotic factors, and that high-throughput studies exploiting yeast systems biology can guide work with hosts (Kramer et al. 2007). Yeast is an established and robust model system in which to study the effects of heterologously expressed proteins, including effectors. Importantly, Liu and coworkers (1992) found that GAL1inducible expression of less than $1 \%$ of yeast genes results in a 
severe growth inhibition phenotype in yeast, which strengthens the possibility that any inhibitory effects due to effector expression will be informative. Moreover, as a heterologous system, yeast lacks the R-protein surveillance system that leads to cell death during the defense response in typical plantpathogen interactions. Therefore, the investigation of cell death associated with the virulence activity of effectors can be examined in the absence of HR activation.

Previously, yeast has been used successfully to study the actions of type III effectors from both plant and animal pathosystems. The seminal papers published by Von PawelRammingen and coworkers (2000) and Lesser and coworkers (2001) demonstrate that the molecular function of the Yersinia effector YopE, to perturb actin dynamics, is conserved in both animals and yeast. Since then, many animal pathogen research groups have exploited yeast as a model system to identify gain-of-function phenotypes, specifically the inhibition of growth or alteration of subcellular processes (Valdivia 2004). Although yeast has not been used systematically in the analysis of plant-associated effectors, two studies have revealed that effectors capable of suppressing the HR in plants are also capable of suppressing apoptosis in yeast (Abramovitch et al. 2003; Jamir et al. 2004).

Here, we have screened the repertoire of DC3000 effectors and identified seven effectors that inhibit the growth of yeast to varying degrees. The enzymatic functions of three of the seven effectors, HopAO1, HopN1, and HopU1, have been previously defined, and catalytic site mutations in HopAO1 and HopN1 resulted in an alleviation of growth inhibition in yeast. Interestingly, four of the seven effectors inhibited respiration in yeast, suggesting that DC3000 effectors may commonly target this biological process. Additionally, we show that overexpression of a previously uncharacterized effector, HopAA1-1, results in a significant reduction in yeast viability. Consistent with its activity in yeast, overexpression of HopAA1-1 also results in cell death in planta and corresponding domains within the protein are required for lethality in both organisms.

\section{RESULTS}

HopAA1-1, HopAD1, HopAM1, HopA01, HopD1, HopN1, and HopU1 show growth-inhibiting activity when expressed in yeast.

To discover new biological activities for DC3000 effectors via a growth inhibition screen in yeast, we first cloned 27 effectors into the high-copy Gateway expression vector pYESDEST52. Following transformation of yeast, individual effectors were expressed under the control of the galactose-inducible $G A L 1$ promoter and protein production was confirmed by immunoblot analysis for all effectors except HopAM1 (Supplementary Fig. S1). To identify those effectors capable of inhibiting the growth of yeast, each yeast culture was serially diluted and plated onto both glucose (repressing) and galactose (inducing) media. All strains exhibited similar growth on repressing media compared with the LacZ-expressing control strain, with the exception of HopAM1-expressing yeast (Fig. 1A). Presumably, leaky expression of hopAMl on repressing media was sufficient to inhibit yeast growth, an interpretation that is consistent with the failure of HopAM1 to accumulate in yeast. Of the 27 DC3000 effectors assayed, expression of only seven, HopAA1-1, HopAD1, HopAM1, HopAO1, HopD1, HopN1, and HopU1, gave a visible growth inhibition phenotype (Fig. 1B). Thus, these seven were chosen for further characterization. As seen in Figure 1 and summarized in Table 1, the inhibition resulting from the expression of these seven effectors varied from virtual abolishment of yeast growth to weaker inhibition and formation of petite colonies.
Mutations affecting the enzymatic activities of HopAO1 and HopN1 eliminate growth inhibition in yeast.

To further test the use of yeast as a model system in which to study DC3000 effector function, we exploited previous work demonstrating the biochemical activities of HopAO1 and HopN1. HopAO1 exhibits protein tyrosine phosphatase activity in vitro (Bretz et al. 2003; Espinosa et al. 2003). A critical residue required for both enzymatic activity and the ability to suppress the HR in planta is $\mathrm{Cys}_{378}$. We recreated the C378S mutation in HopAO1 and tested for its ability to inhibit yeast growth following confirmation of protein expression similar to or greater than wild-type HopAO1 via immunoblot analysis (Supplementary Fig. S2). Mutation of the catalytic cysteine residue to serine eliminated HopAO1-associated growth inhibition in yeast, suggesting that the biochemical activity of HopAO1 is conserved in both yeast and plants (Fig. 2A).

Previous work has shown that HopN1 exhibits cysteine protease activity in vitro (Lopez-Solanilla et al. 2004). Three critical residues for protease activity, $\mathrm{Cys}_{172}, \mathrm{His}_{283}$, and $\mathrm{Asp}_{299}$, compose the catalytic triad of the protein and, when mutated, eliminate the ability of HopN1 to suppress the HR in planta. We expressed the mutant proteins in yeast, confirmed similar amounts of expression via immunoblot analysis, and assayed for growth inhibition (Fig. 2B). In this case, two of the three mutations eliminated the ability of HopN1 to inhibit the growth of yeast. The third mutation, D299A, is known to retain some protease activity in vitro and was not significantly different from wild-type HopN1 in its ability to inhibit the growth of yeast (Lopez-Solanilla et al. 2004). The data suggest that the biochemical activity of HopN1 also is conserved in both yeast and plants, further validating our use of yeast as a useful heterologous system in which to study the activities of phytopathogen effectors. However, it is important to note that the targets or physiological consequences of HopAO1 and HopN1 activity could be different in yeast and plants.

\section{Expression of HopAA1-1 and HopAM1 leads to cell death in yeast.}

Growth inhibition in yeast can occur through either cell death or growth arrest. To identify DC3000 effectors that might play a role in virulence-associated cell death, we set out to define the mode of growth inhibition generated by the expression of each effector. We included in this analysis the seven effectors shown above to inhibit the growth of yeast as well as HopK1 as a negative control. We sampled yeast cultures following $3 \mathrm{~h}$ of induction and determined the percent viability by assaying for the active import of a dye, FUN-1, into the vacuolar compartment (Millard et al. 1997). Compared with the LacZ control, only HopAA1-1 and HopAD1 caused a strong decrease $(>50 \%)$ in the viability of yeast cells, whereas HopAM1 and HopN1 exhibited a more modest yet significant reduction in viability at $3 \mathrm{~h}$ postinduction (Fig. 3A). Interestingly, expression of HopAO1, HopD1, and HopU1 did not result in a significant decrease in yeast viability, even though HopU1 confers strong growth inhibition when plated onto inducing media (Figs. 1B and 3A). It should be noted that the apparent low percent viability for HopAD1-expressing yeast is likely to be an artifact of the assay. We observed rapid photobleaching of FUN-1 fluorescence from red to green (live to dead) in each of the three replicate experiments only for this strain. Therefore, viable cell counts are likely to be vastly underrepresented as compared with the other yeast strains.

To confirm the results obtained with the dye import assay, a plating assay for cell viability was carried out over a 6-h timecourse. Here, induced yeast cultures were sampled by dropping 10-fold serial dilutions onto repressing media every $2 \mathrm{~h}$, and the concentration of CFU per milliliter of the culture was 
determined for each timepoint. If growth inhibition is due to cell death, a decrease in the number of viable cells over time would be expected, as repression of the gene encoding the inhibiting protein by exposure to glucose would not allow for the recovery of dead cells into countable colonies. Alternatively, if growth inhibition is due to growth arrest, a constant number of viable cells would be expected to be present in the culture over time, since depletion of the growth inhibitor would allow the cells to reenter the cell cycle and form colonies. The latter pattern was observed with LacZ-expressing yeast arrested in the cell cycle with $\alpha$-mating factor $2 \mathrm{~h}$ after induction (Fig. 3B). Only HopAA1-1 and HopAM1 demonstrated noticeable lethal activity within $6 \mathrm{~h}$ of induction, whereas HopAD1, HopAO1, HopN1, and HopU1 exhibited a pattern similar to that of cell-cycle arrest (Fig. 3B). HopD1 appeared to have a delayed cell-death phenotype that occurred after $4 \mathrm{~h}$ of induction. HopAD1 did not display lethal effects in the plating assay, which is consistent with our suspicion that photobleaching and not decreased cell viability caused the reduction of red, FUN-1 fluorescence within the vacuolar compartment. However, it should be noted that yeast cells accumulate relatively little HopAD1, and the apparently extreme toxicity of this protein could complicate its analysis.

Taken together, the results of the viability assays demonstrate that expression of HopAA1-1 and to a lesser extent HopAM1 is lethal to yeast within $3 \mathrm{~h}$ of induction, whereas expression of HopAO1, HopU1, and HopAD1 causes growth arrest without apparent cell death throughout $6 \mathrm{~h}$ of induction.

A

Glucose

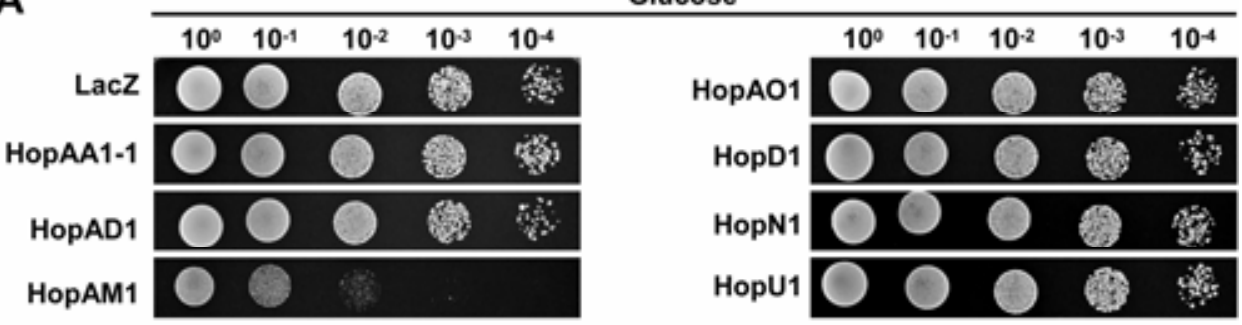

B

Galactose

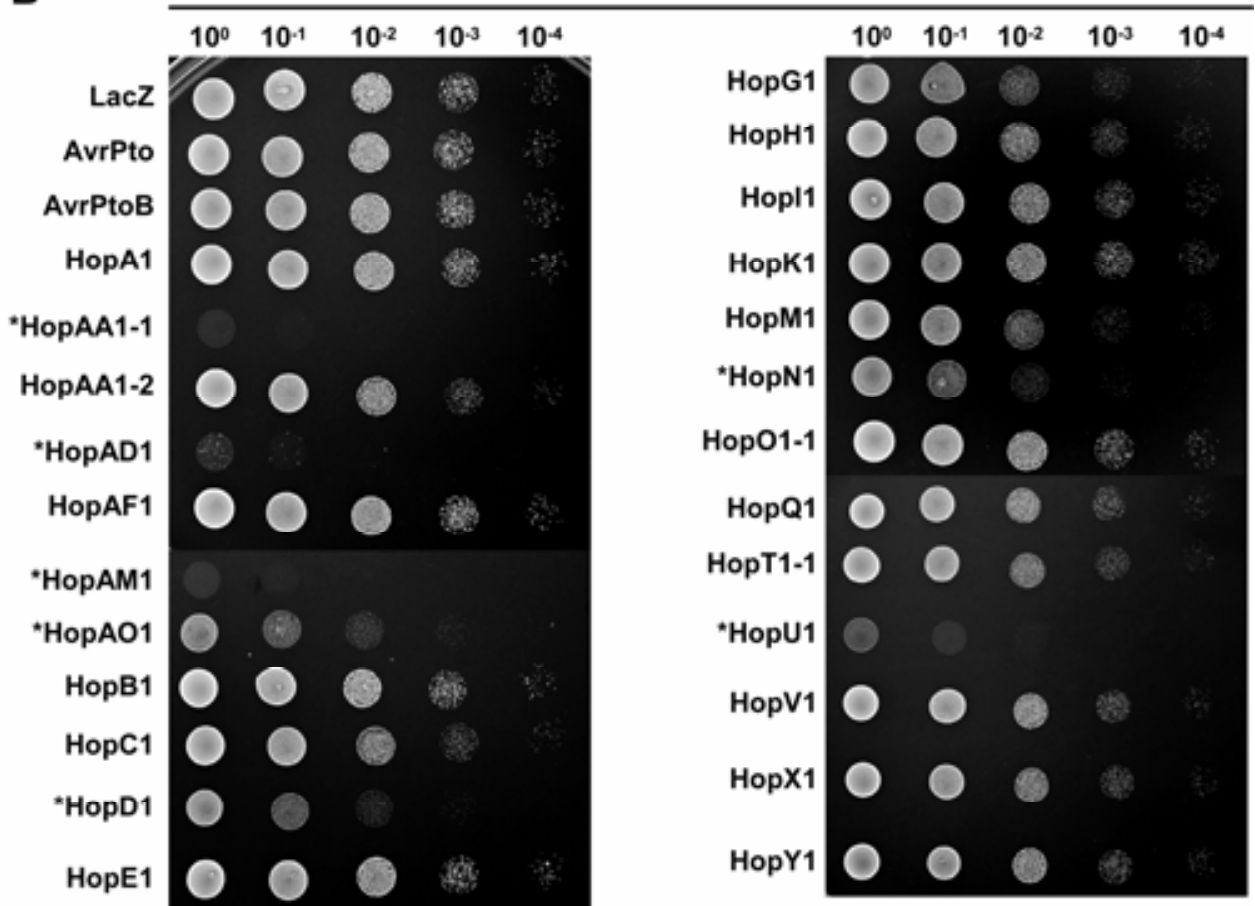

C

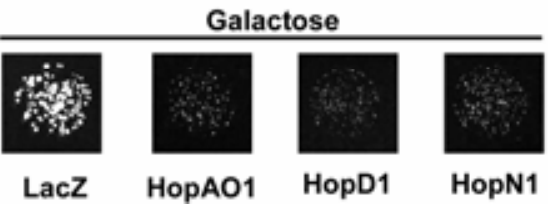

Fig. 1. Expression of seven of the 27 Pseudomonas syringae pv. tomato DC3000 effectors tested inhibits the growth of yeast. Yeast strains (BY4741a) harboring the high-copy plasmid pYES-DEST52 encoding LacZ as a control or DC3000 effectors with a C-terminal V5-epitope tag were grown overnight in selective, noninducing, raffinose media. A, The cultures were normalized to an optical density at $600 \mathrm{~nm}$ of 0.45 , and serial 10-fold dilutions were spotted onto selective media containing glucose to repress or $\mathbf{B}$, galactose to induce the expression of the protein. The data shown represent one of three experiments, all yielding similar results. The seven effectors with inhibitory activity are marked with an asterisk. C, Yeast strains expressing HopAO1, HopD1, and HopN1 exhibit a "petite" phenotype compared with a LacZ-expressing strain. The following dilutions were chosen to show similar numbers of colonies on galactosecontaining media: LacZ at $10^{-4}$; HopAO1, HopD1, and HopN1 at $10^{-3}$. 
Conflicting evidence for HopD1 and HopN1 suggests that longer timecourses are needed to define the mode of growth inhibition brought about by their expression in yeast.

\section{Growth inhibition by $P$. syringae pv. tomato DC3000 effectors is not suppressed}

in a yeast mutant unable to undergo apoptosis.

Next, we sought to determine whether expression of the growth-inhibiting DC3000 effectors initiated apoptosis in yeast. We used a yeast strain disrupted for the metacaspase gene, YCA1, to assay for induction of apoptosis. Caspases and metacaspases have previously been implicated in the regulation of apoptosis in animals, plants, and fungi (Madeo et al. 2004). Disruption of the YCAl metacaspase gene has been shown to prevent apoptosis mediated by various stimuli, including exposure to low doses of hydrogen peroxide, acetic acid treatment, or induction of apoptosis in aging cultures (Madeo et al. 2002). Each growth-inhibiting effector was expressed in a $Y C A 1$-disrupted strain of yeast and was checked for protein expression by immunoblot analysis (data not shown). The YCAl yeast strains were then assayed for significant growth increases compared with wild-type yeast. As a control, YCAl-disrupted yeast was treated with $3 \mathrm{mM} \mathrm{H}_{2} \mathrm{O}_{2}$ and was found to grow significantly more than wild-type cells undergoing the same treatment. However, disruption of YCAl was unable to suppress the growth defects associated with expression of the seven growth-inhibiting DC3000 effectors,

Table 1. Yeast phenotypes induced by overexpression of DC3000 effectors

\begin{tabular}{|c|c|c|}
\hline Effector & Yeast phenotype $^{a}$ & Source \\
\hline AvrE1 & NT & \\
\hline AvrPto & No growth inhibition & This study \\
\hline AvrPtoB & $\begin{array}{l}\text { No growth inhibition; suppression of } \\
\text { oxidative and heat stress induced } \\
\text { lethality }\end{array}$ & $\begin{array}{l}\text { This study; } \\
\text { Abramovitch et } \\
\text { al. } 2003\end{array}$ \\
\hline HopA1 & No growth inhibition & This study \\
\hline HopAA1-1 & $\begin{array}{l}\text { Severe lethality; inhibition of } \\
\text { respiration; mitochondrial localization }\end{array}$ & This study \\
\hline HopAA1-2 & No growth inhibition & This study \\
\hline HopAD1 & $\begin{array}{l}\text { Severe growth inhibition; inhibition of } \\
\text { respiration }\end{array}$ & This study \\
\hline HopAF1 & No growth inhibition & This study \\
\hline HopAM1 & $\begin{array}{l}\text { Severe growth inhibition; inhibition of } \\
\text { respiration }\end{array}$ & This study \\
\hline HopAO1 & $\begin{array}{l}\text { Growth inhibition; petite colonies; } \\
\text { inhibition of respiration }\end{array}$ & This study \\
\hline HopB1 & No growth inhibition & This study \\
\hline HopC1 1 & No growth inhibition & This study \\
\hline HopD1 & $\begin{array}{l}\text { Growth inhibition; petite colonies; } \\
\text { possible localization to ER }\end{array}$ & This study \\
\hline HopE1 & $\begin{array}{l}\text { No growth inhibition; suppression of } \\
\text { Bax induced lethality }\end{array}$ & $\begin{array}{l}\text { This study; } \\
\text { Jamir et al. } 2004\end{array}$ \\
\hline HopF2 & $\begin{array}{l}\text { No growth inhibition; suppression of } \\
\text { Bax induced lethality }\end{array}$ & $\begin{array}{l}\text { This study } \\
\text { Jamir et al. } 2004\end{array}$ \\
\hline HopG1 & $\begin{array}{l}\text { No growth inhibition; suppression of } \\
\text { Bax induced lethality }\end{array}$ & $\begin{array}{l}\text { This study; } \\
\text { Jamir et al. } 2004\end{array}$ \\
\hline HopH1 & No growth inhibition & This study \\
\hline HopI1 & No growth inhibition & This study \\
\hline HopK1 & No growth inhibition & This study \\
\hline HopM1 & No growth inhibition & This study \\
\hline HopN1 & Growth inhibition; petite colonies & This study \\
\hline HopO1-1 & No growth inhibition & This study \\
\hline HopQ1 & No growth inhibition & This study \\
\hline HopR1 & NT & \\
\hline HopT1-1 & No growth inhibition & This study \\
\hline HopU1 & Severe growth inhibition & This study \\
\hline HopV1 & No growth inhibition & This study \\
\hline HopX1 & $\begin{array}{l}\text { No growth inhibition; suppression of } \\
\text { Bax induced lethality }\end{array}$ & This study \\
\hline HopY1 & No growth inhibition & This study \\
\hline
\end{tabular}

${ }^{\mathrm{a}} \mathrm{NT}=$ not tested. indicating that these effectors do not induce apoptosis at a point upstream of $Y C A 1$ (data not shown).

\section{Expression of HopAA1-1, HopAM1, HopAD1, and} HopAO1 impairs respiration in yeast.

During our initial screening, we observed that expression of several of the growth-inhibiting effectors conferred a smallcolony or "petite" phenotype to yeast (Fig. 1C). Petite mutants have been studied in much detail since their discovery over 50 years ago (Ephrussi et al. 1949a and b). The petite phenotype is accompanied by loss of respiration and has been shown to arise from large deletions in or complete loss of mitochondrial DNA, deletion of nuclear genes encoding mitochondrial localized proteins, or perturbation of mitochondrial membranes (Chen and Clark-Walker 2000; Jimenez et al. 1988). To determine whether the growth-inhibiting DC3000 effectors were also inhibiting respiration, expression of the seven growthinhibiting effectors and the HopK1 negative control was induced and cultures were serially diluted and dropped onto ethanol glycerol (EG) selective media. Growth on these nonfermentable carbon sources requires that the yeast be respiration competent. Induced expression of one effector causing a
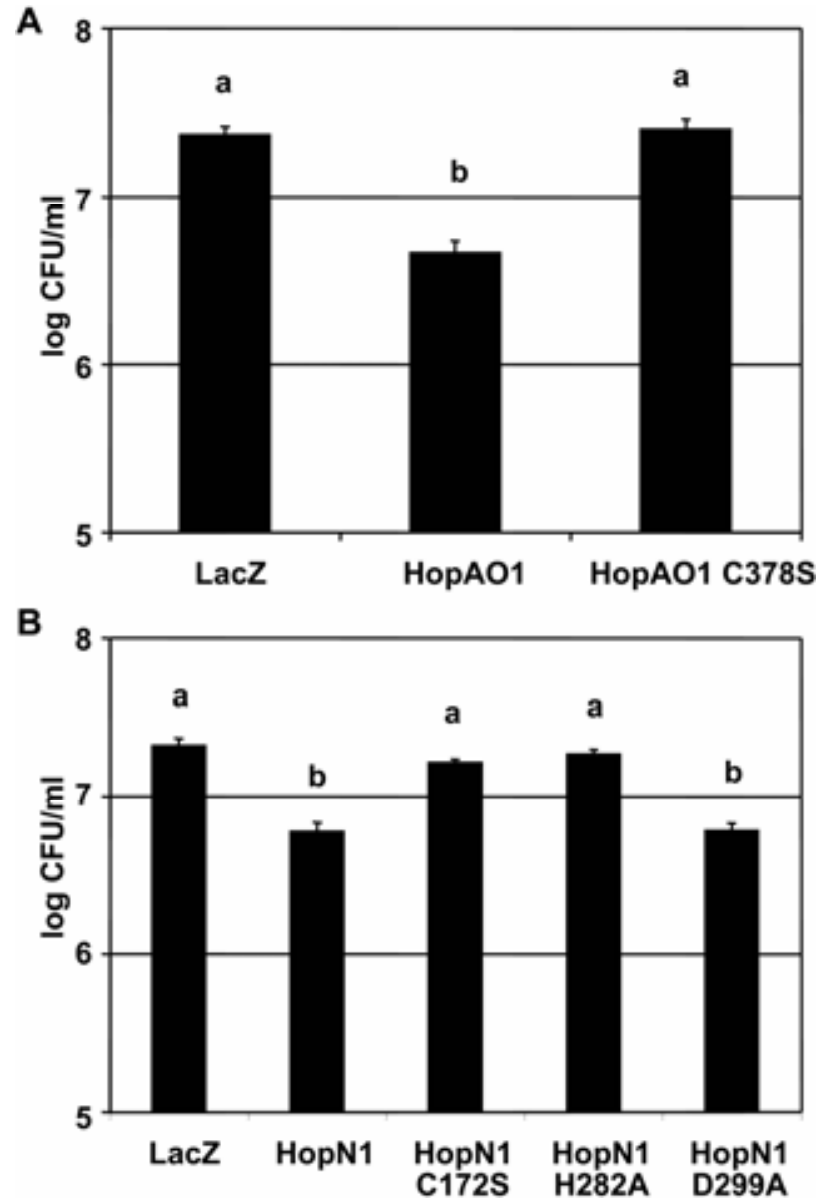

Fig. 2. A, Mutations affecting critical residues for enzymatic activity of HopAO1 and $\mathbf{B}$, HopN1 also eliminate growth inhibition in yeast. Yeast strains were grown overnight in selective, noninducing, raffinose media. The cultures were normalized to an optical density at $600 \mathrm{~nm}$ of 0.45 , and serial 10-fold dilutions were spotted onto selective media containing glucose to repress (data not shown) or galactose to induce the expression of the protein. Error bars designate standard error over three individual experiments. One-way analysis of variance was carried out using PROC GLM with Tukey's correction for multiple comparisons in the SAS statistical package ( 9.1 for Windows). Means with the same letter are not significantly different at a significance level $\leq 0.05$. B, Prior to analysis a transformation of the data was performed to meet normality assumptions. 
A

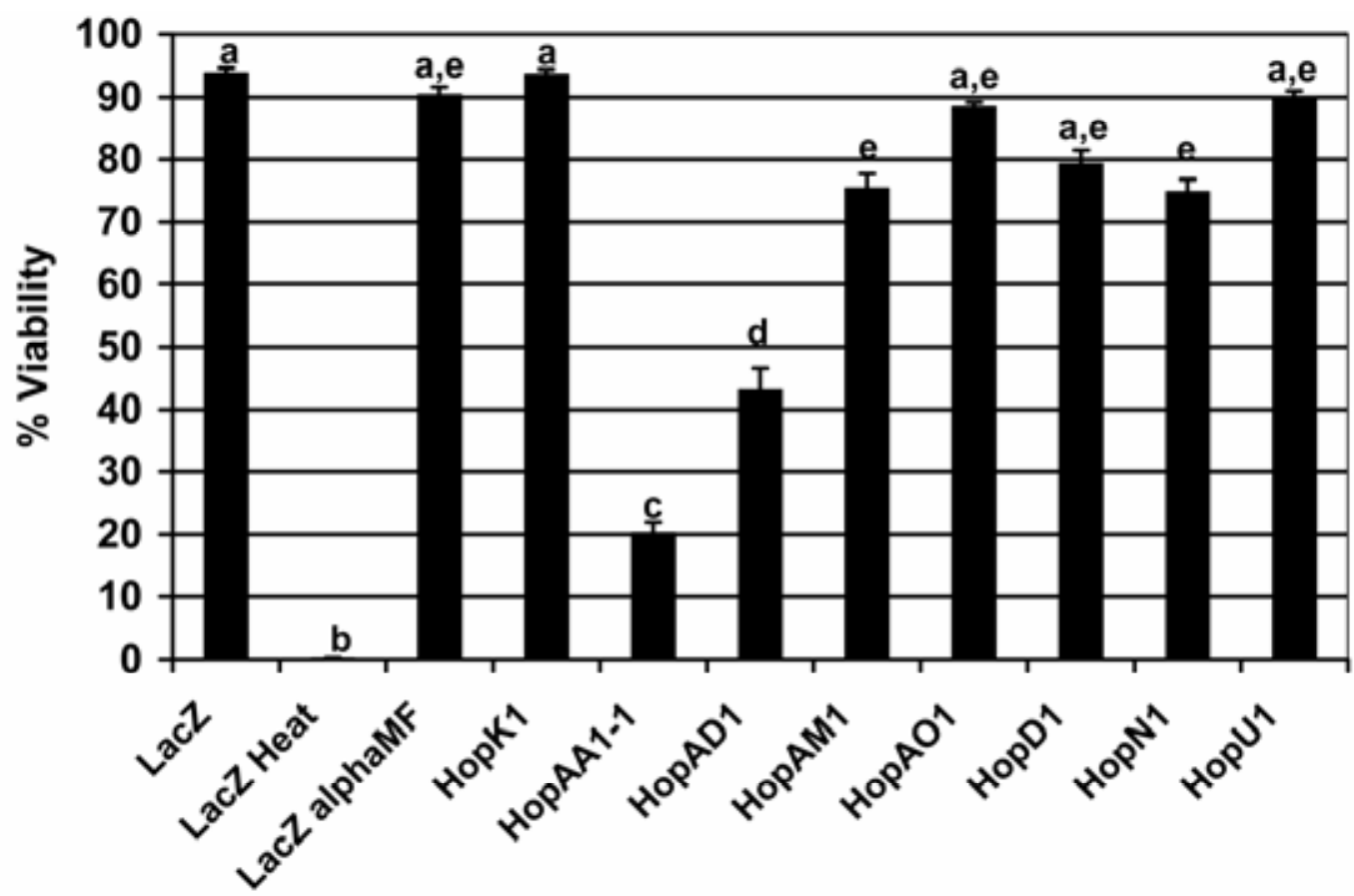

B

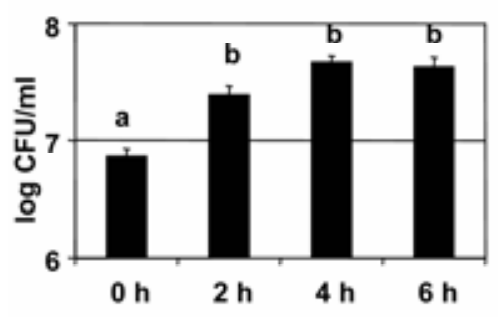

HopAD1

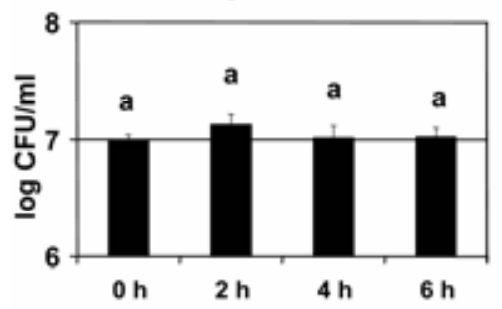

HopD1
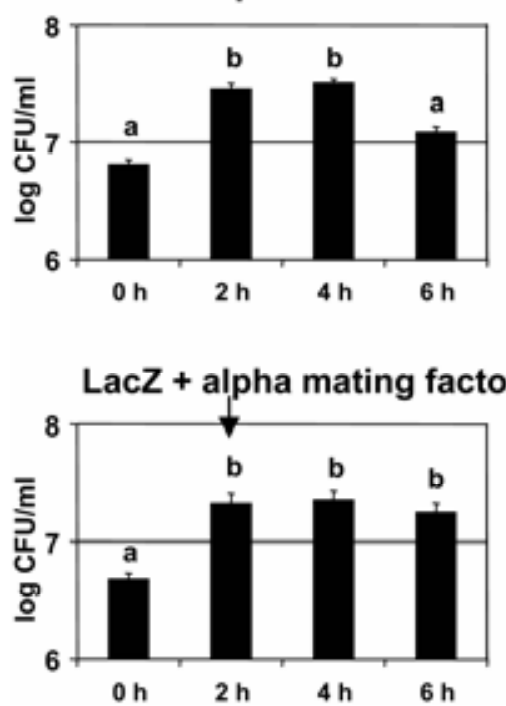

HopK1

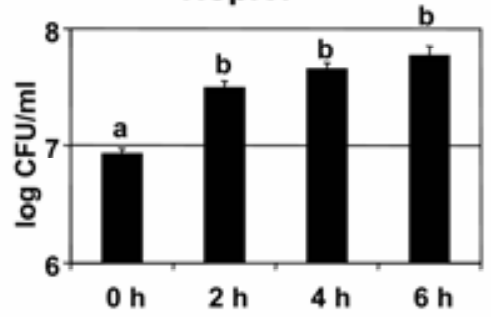

HopAM1

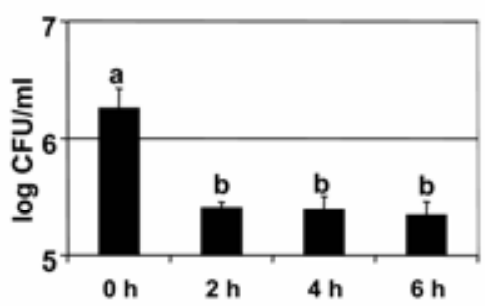

HopN1

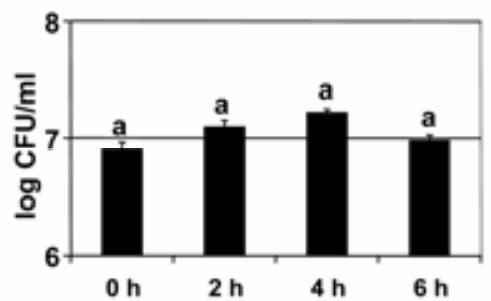

HopAA1-1

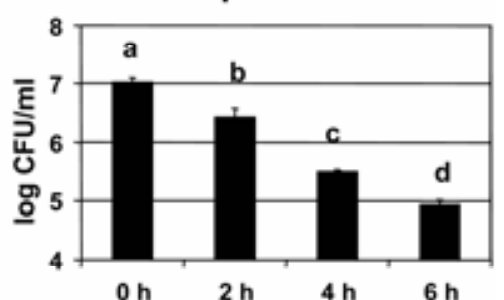

HopAO1

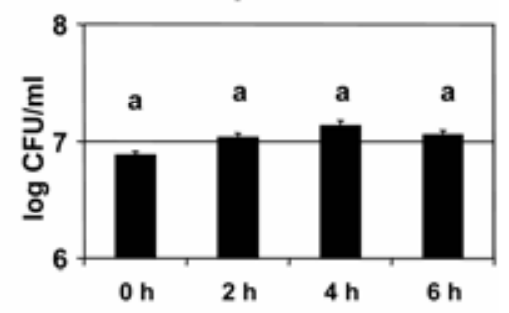

HopU1

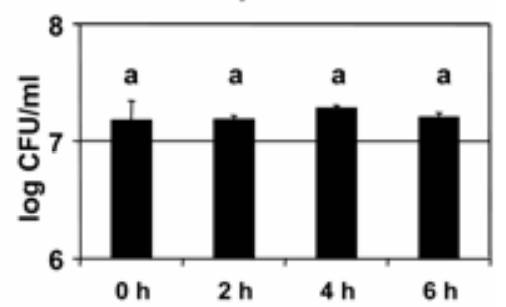


petite phenotype, HopAO1, also resulted in inhibition of respiration. Surprisingly, expression of three other effectors, HopAA1-1, HopAM1, and HopAD1, resulted in a dramatic loss of respiration even prior to induction with galactose (Fig. 4). In this case, leaky expression that is presumed to occur in the presence of raffinose, a sugar that neither induces nor represses expression from the GALl promoter, was sufficient to inhibit respiration in these strains, while growth on glucose remained normal (or was substantially less inhibited in the case of HopAM1) (Fig. 4). These results suggest that four DC3000

Fig. 3. Assessment of yeast viability upon expression of Pseudomonas syringae pv. tomato DC3000 effectors that inhibit the growth of yeast. A, Yeast expressing DC3000 effectors was assayed for the ability to form FUN1-dependent cylindrical structures in the vacuolar compartment 3 h postinduction with galactose as an indicator of viability. Error bars designate standard error over three individual experiments. Because there was no significant block effect, one way analysis of variance was carried out using PROC GLM with Tukey's correction for multiple comparisons in the SAS statistical package (9.1 for Windows). Means with the same letter are not significantly different at a significance level $\leq 0.05$. B, Yeast strains were grown overnight in selective, noninducing, raffinose media. Cultures were allowed to recover in fresh media for $2 \mathrm{~h}$ prior to normalization to optical density at $600 \mathrm{~nm}$ of 0.2 and induction with galactose. For each timepoint, a portion of the culture was removed and serial 10-fold dilutions were spotted onto selective, glucose media to repress expression. The arrow indicates the time at which alpha-mating factor was added to the LacZ-expressing culture to arrest the cells. Error bars designate standard error over three individual experiments. Repeated measures analysis of variance was carried out using the MIXED procedure with Bonferoni's correction for multiple comparisons in the SAS statistical package. The data was log transformed prior to statistical analysis, and no significant block effect was observed. Means within each histogram with the same letter are not significantly different at a significance level $\leq 0.05$.
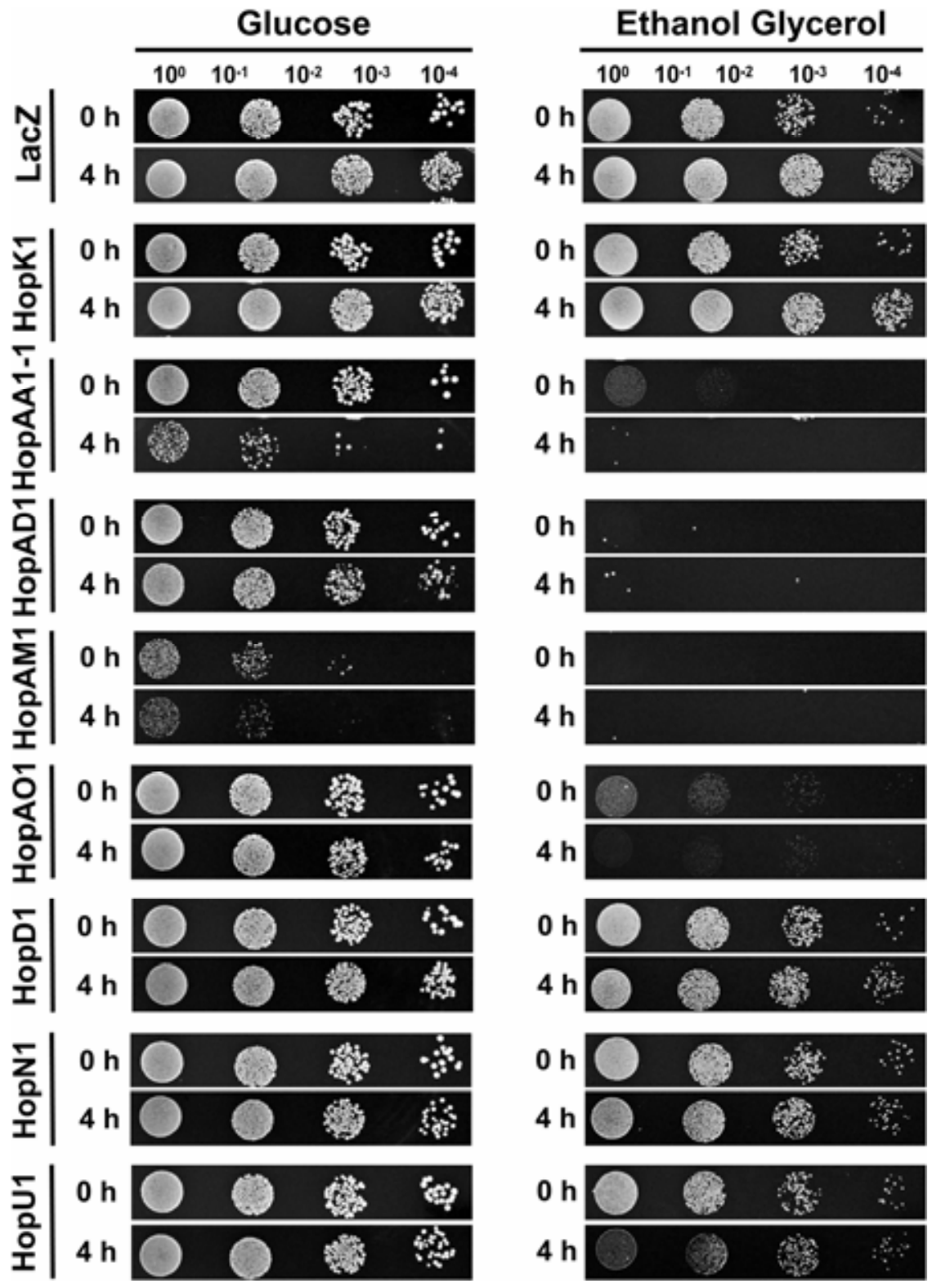

Fig. 4. Expression of HopAA1-1, HopAD1, HopAM1, and HopAO1 compromises respiration in yeast. The HopK1 control and the seven effectors exhibiting growth inhibition when expressed in yeast were assayed for their effects on respiration. Yeast strains were grown overnight in selective, noninducing, raffinose media. Cultures were allowed to recover in fresh media for $2 \mathrm{~h}$ prior to normalization to an optical density at $600 \mathrm{~nm}$ of 0.2 and induction with galactose. At 0 and $4 \mathrm{~h}$ postinduction with galactose, an aliquot of the culture was removed, and serial 10 -fold dilutions were spotted onto selective, glucose plates as a control or ethanol-glycerol media to select for respiration-competent cells. 

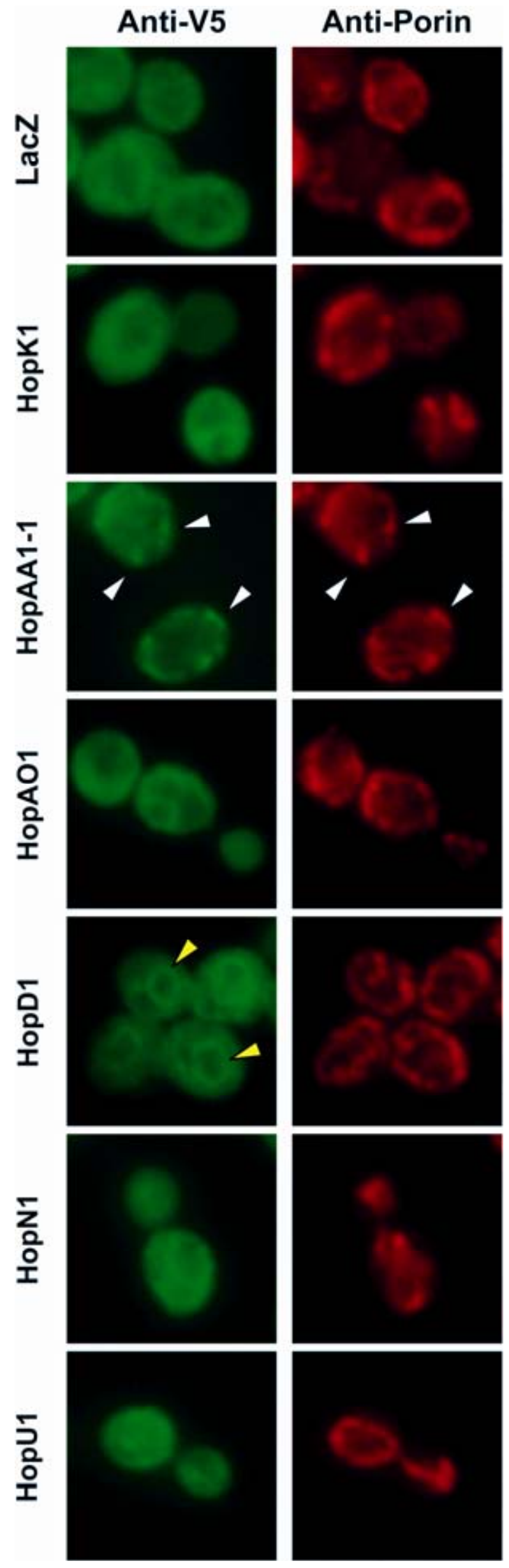

effectors target one or more biological processes in yeast associated with respiration.

\section{HopAA1-1 localizes to yeast mitochondria.}

We chose to examine the lethal activity of HopAA1-1 in yeast in more detail for several reasons. Prior work has shown that hopAA1-1 sequences are present in diverse $P$. syringae pathovars (Badel et al. 2002; Rohmer et al. 2004; Sarkar et al. 2006). Consequently, the activity of HopAA1-1 is expected to confer some selective advantage to $P$. syringae in its T3SSmediated interactions with plants. Yet, previous work has shown

Fig. 5. HopAA1-1 colocalizes with a mitochondrial protein in yeast. DC3000 effectors that inhibited growth of yeast were assayed for colocalization with the mitochondrial protein porin. Green fluorescence in the left panels represents localization of the effector-V5-6His fusion proteins. Red fluorescence in right panels represents localization of porin in the same cells. White arrows indicate colocalization of the V5 and porin antibodies when a HopAA1-1-V5 fusion protein is expressed in yeast. Yellow arrows indicate localization patterns similar to that observed for endoplasmic reticulum-localized proteins.

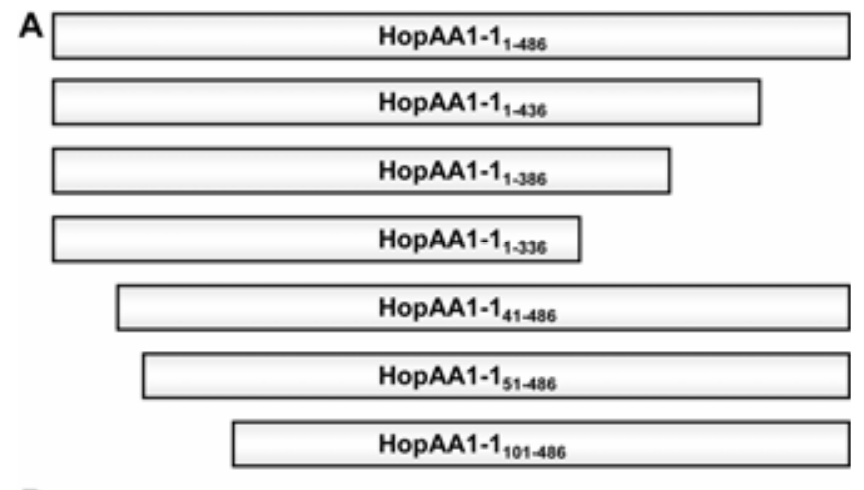

B

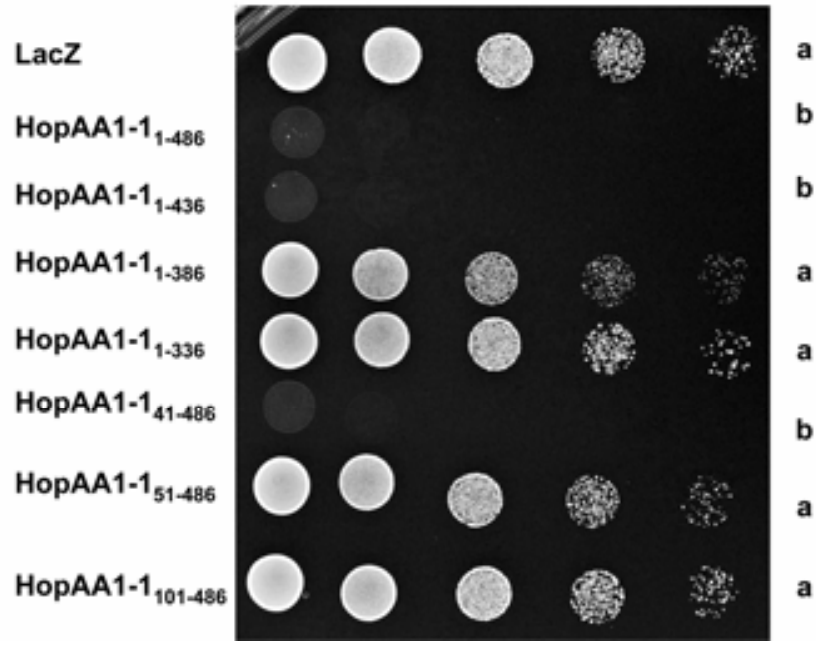

Fig. 6. Only HopAA1-1 proteins with small truncations at either termini retain lethal activity in yeast. A, The indicated hopAAl-1 derivatives were cloned into pYES-DEST52 and were transformed into yeast. B, Strains were grown overnight in selective, noninducing, raffinose media. The cultures were normalized to an optical density at $600 \mathrm{~nm}$ of 0.45 , and serial 10 -fold dilutions were spotted onto selective media containing galactose to induce the expression of the protein. The experiment was repeated two more times with similar results. One-way analysis of variance was carried out using PROC GLM with Tukey's correction for multiple comparisons in the SAS statistical package (9.1 for Windows). The same letter (to the right of the figure) indicates that means over three experiments are not significantly different at a significance level $\leq 0.05$. 
that a double mutant of hopAA1-1 and its paralog, hopAA1-2, in DC3000 resulted in a strain exhibiting only the subtle phenotype of reduced colony initiation in planta with no significant reduction in symptom formation or final bacterial growth (Badel et al. 2002). Thus, HopAA1-1 is representative of many $P$. syringae effectors, for which loss-of function mutants have revealed little about the function of the protein in plant tests and exploring a biological activity in yeast provides an alternative route to uncovering the function of the effector.

Importantly, the ability of HopAA1-1 to inhibit respiration in yeast suggested that it might be acting on mitochondria, which are the site of respiration and have not previously been shown to be a target for $P$. syringae effectors. Thus, we investigated the potential localization of HopAA1-1 to mitochondria in yeast. Immunofluorescence analysis was carried out with an antibody to the V5-epitope tag fused to the C-terminal end of HopAA1-1. HopAA1-1 localized in a distinct manner to punctate structures at the periphery of the yeast cell. We were able to colocalize the yeast mitochondrial porin protein to the same structures, indicating that HopAA1-1 was associating with mitochondria in yeast (Fig. 5).

Because mitochondria are thought to have arisen from a prokaryotic endosymbiont and effector proteins originate within a prokaryotic organism, we wondered if all effectors associate with yeast mitochondria, possibly through their N-terminal type III secretion signal. To test this hypothesis, we analyzed the localization patterns of each of the growth-inhibiting effectors as well as the HopK1 negative control and found that only HopAA1-1 colocalized with mitochondrial porin (Fig. 5). The low expression of HopAD1 and HopAM1, which had been seen previously for both proteins in immunoblot analysis, prevented us from determining their subcellular localization. However, the remaining respiration inhibiting effector, HopAO1, did not localize to mitochondria, indicating that HopAA1-1 and HopAO1 may function in different manners to inhibit respiration. Interestingly, the localization of HopD1 in yeast is reminiscent of endoplasmic reticulum-localized proteins (Yeast GFP Fusion Localization Database; Huh et al. 2003).

\section{Similar regions of HopAA1-1 are required for cell death in both yeast and plants.}

Next, we chose to define the regions of HopAA1-1 necessary for cell death in yeast. Successive truncations were created from both ends of the gene (Fig. 6A) and similar levels of expression were confirmed for each by immunoblot analysis (Supplementary Fig. S3). Only HopAA1-1 derivatives with relatively small deletions, 40 amino acids from the $\mathrm{N}$ terminus and 50 amino acids from the $\mathrm{C}$ terminus of the protein, retained the ability to cause cell death in yeast (Fig. 6B).

Next, we tested for the ability of HopAA1-1 to kill plant cells. Both full-length and truncated derivatives of hopAA1-1 were expressed in plant cells via Agrobacterium-mediated transient expression in Nicotiana benthamiana, which is a host for P. syringae pv. tomato DC3000 strains lacking the HopQ11 avirulence determinant (Wei et al. 2007). Similar levels of accumulation of each protein in planta were confirmed by immunoblot analysis (Supplementary Fig. S4). Interestingly, the same pattern of cell-death activity that was observed for the panel of deletion derivatives in yeast was also observed when HopAA1-1 was expressed in plants (Fig. 7A), which suggests that the action of HopAA1-1 is similar in plants and in yeast. Furthermore, cell death associated with full-length HopAA1-1 expression was also observed in both the nonhost plant, Nicotiana tabacum L. cv. Xanthi, and in the host plant, tomato (Fig. 7B), indicating that HopAA1-1 causes cell death when transiently expressed in multiple plants. These results demonstrate once more the connection between DC3000 ef- fector function in yeast and plants and implicate HopAA1-1 as a protein capable of initiating cell death across eukaryotic kingdoms.

\section{DISCUSSION}

Our screen for type III effectors that inhibit the growth of yeast encompassed almost the entire currently accepted repertoire of $P$. syringae pv. tomato DC3000 effectors (Chang et al. 2005; Ferreira et al. 2006; Schechter et al. 2006). However, two members of the repertoire, AvrE1 and HopR1, were not included due to difficulties in cloning full-length genes, as has been reported previously (Chang et al. 2005). We found that approximately $25 \%$ of the tested effectors inhibited yeast growth at least partially and $15 \%$ of the effectors inhibited yeast growth completely (Table 1). Similarly, three of five Yersinia effector proteins tested lead to growth inhibition when expressed in yeast (Lesser and Miller 2001). In comparison, overexpression of fewer than $1 \%$ of yeast proteins completely inhibit the growth of yeast (Liu et al. 1992). The large proportion of DC3000 effectors that inhibited the growth of yeast suggests that these proteins are disrupting cellular targets that are broadly conserved and important in eukaryotes.

Among the effectors tested were two with known enzymatic functions, HopAO1 and HopN1. In both cases, catalytic-site point mutations interfered with the inhibitory effects of the proteins in yeast. Specifically, we demonstrated that a residue required for the protein tyrosine phosphatase activity of HopAO1 and its ability to suppress the HR in plants is also required for inhibition of yeast growth (Bretz et al. 2003; Espinosa et al. 2003). Similarly, two of the three critical residues for cysteine protease activity of HopN1 that are required

A

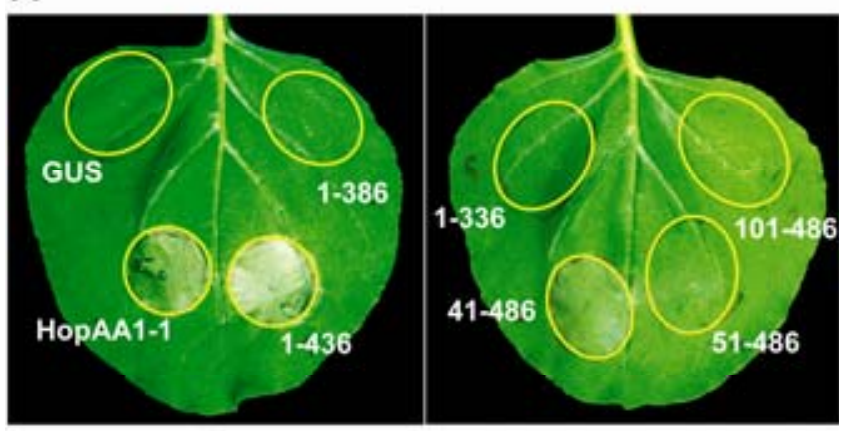

B

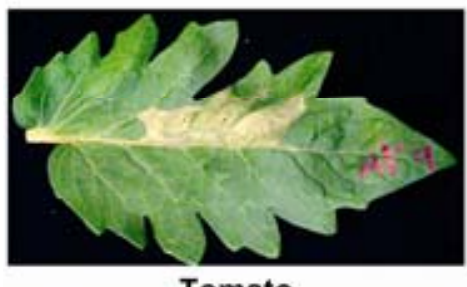

Tomato

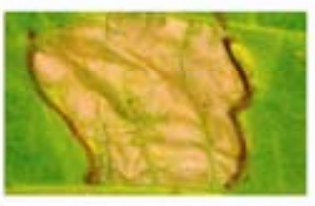

Tobacco

Fig. 7. Domain-dependent cell death induced by HopAA1-1 follows the same pattern in plants and yeast. A, The hopAA1-1 truncations indicated were cloned into pLN462 and were expressed from the Cauliflower mosaic virus $35 \mathrm{~S}$ promoter via Agrobacterium-mediated transient expression in Nicotiana benthamiana leaves. The infiltrated area is designated with yellow circles. Each set of constructs was infiltrated on at least three plants per experiment. The experiment was repeated at least three times with similar results. B, Agrobacterium-mediated transient expression of fulllength HopAA1-1 constructs was carried out as in A in tomato (cv. Moneymaker) and tobacco (cv. Xanthi). Each construct was infiltrated on at least two leaves on two plants per experiment. The experiment was repeated at least three times with similar results. 
for cell death-suppressing activity in plants are also required for the protein's ability to inhibit the growth of yeast (LopezSolanilla et al. 2004). It is paradoxical that, for each of these proteins, the same catalytic activity that has a protective effect in plants has a deleterious effect in yeast. There are several possible explanations for this discrepancy. One is that the low levels of each protein that are delivered to plant cells by the T3SS are sufficient to disrupt programmed cell-death signaling without harming the cells, whereas the much higher levels of protein produced in transformed yeast are toxic. Another possibility is that the targets are functionally distinct in plants and yeast.

An example of the latter explanation can be found in the Yersinia effector YopJ. YopJ has been shown to inhibit mitogen-activated protein (MAP) kinase pathways in both yeast and host cells. However, the targeted host pathways lead to the induction of both innate and adaptive immunity in animals, whereas the targeted pathways in yeast are involved in mating pheromone signaling and growth under high osmolarity conditions (Orth 2002; Yoon et al. 2003). That is, whereas YopJ appears to have a conserved activity in animals and yeast, the targets and downstream effects clearly differ. Thus, although yeast provides a powerful tool for finding clues to the functions of type III effectors, these clues need to be confirmed in host cells.

There are two examples in which such confirmation has been provided. First, yeast was used successfully to identify a eukaryotic activator of the $P$. syringae effector protein AvrRpt2, which functions similarly in plants. Specifically, incubation with the yeast activation factor cyclophilin or its homolog in Arabidopsis, ROC1, is sufficient for activating AvrRpt 2 cysteine protease activity, self-cleavage, and cleavage of the plant substrate RIN4 in vitro (Coaker et al. 2005). The characterization of the Yersinia effector YopT provides an additional example of the successful use of yeast to define the effector function. YopT exhibits cytotoxicity when delivered into host cells and growth inhibition when expressed in yeast (Shao et al. 2002). Shao and coworkers (2002) used a multicopy suppressor approach to identify targets of this protein in yeast. The yeast Rho GTPase Cdc42p was identified as a suppressor of YopT-induced growth inhibition, and mammalian Rho GTPases were shown to be targets of the effector in host cells. These two examples highlight the value of yeast in studying type III effector function.

Here, we chose to examine further the activity in yeast of HopAA1-1, an effector of unknown biochemical function that is one of seven effectors broadly conserved in $P$. syringae pathovars (Lindeberg et al. 2006). Similar regions of HopAA11 were shown to be required to cause cell death in yeast and plants. Recent findings show that Agrobacterium-mediated transient expression of HopAA1 from $P$. syringae pv. syringae B728a (74\% identity, $82 \%$ similarity with HopAA1-1 from DC3000) induces cell death in both tobacco and $N$. benthamiana leaves that is dependent on EDS1 but not SGT1 (Vinatzer et al. 2006). Interestingly, the effector acts as a weak avirulence determinant in $N$. benthamiana under conditions in which spray inoculum is used, suggesting that the cell death phenotype is due to elicitation of the HR. Similarly, we have observed the suppression of HopAA1-1-associated cell death in EDS1 but not SGT1-silenced $N$. benthamiana plants (data not shown). Because SGT1 appears to be required for the elicitation of the HR by many known $a v r / R$-gene pairs tested, elicitation of cell death by HopAA1-1 may be independent of the anti-effector $R$-gene surveillance system. It has recently been shown that the suppression of reactive oxygen species generation in response to flg22 by AvrPtoB requires EDS1 in N. benthamiana plants (Hann and Rathjen 2007). Although the molecular mechanism for the dependence of this virulence activity on EDS1 remains undefined, the results suggest that EDS1 may play a role in both the recognition and virulence activity of some effectors. A requirement for EDS1 in the suppression of basal defenses by some effectors is particularly interesting here because HopAA1-1 was reported to be one of nine DC3000 effectors that were found to suppress flg22induced expression of $\mathrm{NHOl}$ (nonhost resistance) when expressed in Arabidopsis protoplasts ( $\mathrm{Li}$ et al. 2005). However, given the observations that HopAA1-1 causes death in plant cells (Vinatzer et al. 2006; Wei et al. 2007; Fig. 7), the apparent suppression of $\mathrm{NHOl}$ expression (or other basal defense markers) by HopAA1-1 may be open to alternative explanations.

Whether or not HopAA1-1 from DC3000 is eliciting the HR in tomato, tobacco, and $N$. benthamiana, yeast is not thought to possess anti-effector R-protein sentinels, which would suggest that the HopAA1-1 cell-killing ability is unrelated in yeast and plants. However, the guard hypothesis offers the possibility for a relationship. The guard hypothesis states that the virulence activity of effectors on host targets, not the effectors themselves, is recognized by plant $\mathrm{R}$ proteins, which leads to elicitation of the HR (Van der Biezen and Jones 1998). Therefore, it is possible that cell death elicited by HopAA1-1 expression in both yeast and plants results from the virulence activity of the protein, even though $\mathrm{R}$ protein recognition of that activity may amplify the cell killing in plants. In fact, the use of yeast to study the function of this effector may be particularly advantageous, because it permits focus on the activity of HopAA1-1 with primary targets without complications arising from HR elicitation by an unknown $\mathrm{R}$ protein in plants.

We also found that HopAA1-1 colocalizes with the yeast mitochondrial protein porin. HopAA1-1 localization to mitochondria, the site of respiration in yeast, is in line with evidence that HopAA1-1 inhibits respiration in yeast at low levels of expression. The cell-killing activity of HopAA1-1 in plant cells has, so far, prevented us from confirming mitochondrial localization of HopAA1-1 in plants. Previously, Guttman and coworkers (2002) analyzed candidate effectors using TargetP and found that 13 of 16 effectors were predicted to localize to either the chloroplast or mitochondrion. The N-terminal signal sequence that directs effectors to the T3SS may exhibit enough resemblance to chloroplast or mitochondrial import signals so that many effectors are predicted to localize to these organelles by programs such as TargetP (Emanuelsson et al. 2000; Nielsen et al. 1997). To date, only one $P$. syringae effector has been shown to localize to a plant organelle. Recent work demonstrates that the $P$. syringae pv. syringae B728a effector HopI1 localizes to chloroplasts, in which it actively suppresses salicylic acid (SA)-dependent defenses (Jelenska et al. 2007). To our knowledge, no evidence exists for localization of plantpathogen effectors to plant mitochondria.

In contrast, several effectors from animal pathogens have been shown to localize to mitochondria. Pathogenic Escherichia coli strains express two effectors, MAP and EspF, that localize to mitochondria in which they are known to disrupt mitochondrial membrane potential (Kenny and Jepson 2000; Ma et al. 2006a; Nagai et al. 2005; Nougayrede and Donnenberg 2004). In addition, the Salmonella effector SopA localizes to mitochondria, although the implications of localization in pathogenesis have not been determined at this time (Layton et al. 2005). Interestingly, not all functions associated with EspF are reliant on mitochondrial localization (Quitard et al. 2006). It is possible that temporal localization may regulate the multiple functions of this effector.

Four of the seven DC3000 effectors that inhibited yeast growth, including HopAA1-1, also inhibited yeast respiration. The fact that this phenotype occurs in media containing raffi- 
nose, a sugar that neither induces nor represses expression from the GALl promoter, as the only carbon source suggests that the effectors are acting at very low levels of expression to inhibit respiration. Yeast preferentially uses fermentation to metabolize carbon substrates even under aerobic conditions. When confronted with a nonfermentable carbon source such as ethanol glycerol media, yeast is restricted to respiration for energy production. Consequently, yeast that are respiration-deficient often exhibit no growth reduction in the fermentable media typically used to grow yeast. It will be interesting to assay the remaining DC3000 effectors that were not identified as inhibitors of growth for their ability to disrupt respiration in yeast.

Respiratory capacity has been implicated in plant defense responses to pathogens. Atkinson and Baker (1989) demonstrated that respiratory inhibitors reduce the incidence of an early marker of $\mathrm{HR}$ induction, the $\mathrm{K}^{+}$efflux/net $\mathrm{H}^{+}$uptake exchange that occurs upon infection with an incompatible strain of $P$. syringae. However, inhibition of cyanide-resistant respiration did not significantly affect this ion exchange. Furthermore, oxygen uptake induced upon treatment of suspension culture cells with heat-killed bacteria relies on a functional cytochrome- $c$ respiration pathway (Baker et al. 2000).

In contrast, SA treatment has been shown to increase cyanide-resistant respiration in plants. In fact, a gene encoding alternative oxidase, which acts as the terminal acceptor of electrons in cyanide-resistant respiration, has been shown to have promoter elements similar to SA-inducible PR genes (Rhoads and McIntosh 1993). Furthermore, inhibition of alternative oxidase in tobacco results in a decrease of SA-induced resistance to Tobacco mosaic virus (Chivasa et al. 1997). Both cytochrome $c$-dependent and alternative oxidase-dependent respiration pathways were induced during both incompatible and compatible interactions between $P$. syringae and Arabidopsis. Induction was delayed, however, in the compatible interaction as compared with the incompatible interaction (Simons et al. 1999). The interplay between cytochrome $c$-dependent and alternative oxidase-dependent respiration pathways during pathogen attack is likely to be complex. However, both pathways have been linked to defense and represent potential targets for DC3000 effectors.

Do DC3000 effectors commonly target the respiratory process in compatible interactions? According to Cohn and Martin (2005), $15 \%$ of tomato genes downregulated in response to the Hrp regulon of DC3000 are involved in basic metabolism. Interestingly, cytochrome $c$ expression is downregulated by the Hrp regulon of DC3000 but remains unaffected by avrPto or avrPtoB expression. Cytochrome $c$ is required for functional electron transport during respiration, and its release from mitochondria is a common marker of programmed cell death in animals, fungi, and plants (Hoeberichts and Woltering 2003). Whether downregulation of this and other genes involved in respiration is associated with the activity of the effectors identified in this screen is of significant interest. Direct assays for the alteration of respiration in plant cells by DC3000 effectors must be undertaken in the future to address this question.

\section{MATERIALS AND METHODS}

\section{Plasmids, strains, and media.}

The strains and plasmids used in this study are described in Supplementary Table S1. All cloned plasmids were maintained in E. coli DH5 $\alpha$, except for pYES-DEST52 and pCPP5279, which were maintained in E. coli DB3.1, and pCPP5627, which was maintained in E. coli XL1-Blue. E. coli and Agrobacterium tumefaciens strains were grown in Luria Bertani (LB) and were incubated at 37 and $30^{\circ} \mathrm{C}$, respectively (Sambrook et al. 1989).
The following antibiotic concentrations $(\mu \mathrm{g} / \mathrm{ml})$ were used for all E. coli and A. tumefaciens strains: ampicillin, 100; chloramphenicol, 20; kanamycin, 50; rifampicin, 50; and gentamycin, 10.

Yeast strains were grown in drop-out base (DOB) media (Qbiogene, Morgan Irvine, CA, U.S.A.; Sunrise Science Products, San Diego, CA, U.S.A.) containing $2 \%$ glucose (glc), $2 \%$ raffinose (raf), or $1 \%$ raf and $2 \%$ galactose (gal) as carbon sources. Media was supplemented with complete supplement mixture (CSM) lacking uracil (-ura) to maintain the plasmid. Ethanol glycerol (EG) media was equivalent to synthetic defined (SD) medium (Sherman 2002) with 3\% ethanol and 3\% glycerol replacing glc as the carbon source and supplemented with CSM -ura. Yeast strains were incubated at $30^{\circ} \mathrm{C}$ in all cases.

\section{DNA manipulations.}

All DNA manipulations were performed according to standard techniques (Sambrook et al. 1989). Polymerase chain reaction (PCR) amplification for entry vector construction was carried out using primers purchased from Integrated DNA Technologies (Skokie, IL, U.S.A.) and either Deep Vent DNA polymerase (New England Biolabs, Ipswich, MA, U.S.A.) or cloned Pfu DNA polymerase (Stratagene, La Jolla, CA, U.S.A.). Sequencing was performed at the Cornell University Biotechnology Resource Center with an Applied Biosystems Automated 3730 DNA analyzer. Sequence data was analyzed using Sequencher 4.2.2 software (Gene Codes Corp., Ann Arbor, MI, U.S.A.).

\section{Plasmid construction.}

Several methods were used to create Gateway entry vectors for the genes tested in this work. First, the sequence of each of the DC3000 effectors except avrPto, hopAMl, and hopCl was PCR-amplified from DC3000 genomic DNA. Forward primers were designed to each full gene corresponding to the $5^{\prime} 15$ to 25 nucleotides, including a $5^{\prime}$ extension of CACC. Reverse primers were designed corresponding to the $3^{\prime} 15$ to $25 \mathrm{nt}$ of the gene, lacking the stop codon. PCR products were cloned into $\mathrm{pENTR/SD/D-TOPO}$ via the directional TOPO cloning reaction (Invitrogen, Carlsbad, CA, U.S.A.). hopAAl-1 truncations were PCR-amplified from pCPP5107 template DNA and were cloned into $\mathrm{pENTR/SD/D-TOPO}$ in the manner described above. Second, cloning of avrPto, hopAM1, and hopCl into pDONR201 was carried out by amplification of each effector from genomic DNA using primers corresponding to 15 to 25 nucleotides of the $5^{\prime}$ and $3^{\prime}$ ends of the full gene, lacking the stop codon. Both forward and reverse primers contained extensions consisting of $a t t B$ recombination sites to be used in the $\mathrm{BP}$ recombination reaction (Invitrogen). To generate mutations within hopAO1 and hopN1, the entry vectors pCPP5537 and pCPP5619 were modified with QuikChange site-directed mutagenesis kit (Stratagene). All entry clones were confirmed by DNA sequencing. Expression vectors were constructed by recombining each entry vector into the Gateway destination vector pYES-DEST52 via the Gateway LR recombination reaction (Invitrogen).

The pCPP5279 plant expression vector was made by inserting eGFP lacking the start codon amplified from pEGFP-N1 (Clontech, Mountain View, CA, U.S.A.) with XbaI adapters. The PCR fragment was digested and cloned into the $X b a I$ site of the pBTEX binary vector already containing Gateway reading frame B (Invitrogen). pCPP5107 was then recombined with pCPP5279 via the LR recombination reaction to create a vector expressing HopAA1-1 eGFP from the $35 \mathrm{~S}$ promoter. LR reactions were also carried out with pLN462 (Jamir et al. 2004) to generate plant expression vectors for the hopAA1-1 truncations fused to a C-terminal HA tag. 
Yeast growth inhibition assays.

pYES-DEST52-based expression vectors carrying DC3000 effectors and LacZ were transformed into the $S$. cerevisiae strains BY4741a, KFY715, and KFY729 by the lithium acetate transformation method (Gietz et al. 1992). Transformation reactions were plated onto solid DOB glc -ura media to select for maintenance of the plasmid. For standard growth inhibition experiments (Figs. 1, 2, and 6B and yca1 experiments), strains were incubated overnight with shaking in DOB glc -ura liquid culture, were subinoculated, and were incubated overnight with shaking in DOB raf -ura liquid culture. All cultures were normalized to optical densities at $600 \mathrm{~nm}\left(\mathrm{OD}_{600}\right)$ of 0.45 , using a Spectronic 20 (Bausch \& Lomb, Rochester, NY, U.S.A.) in DOB raf -ura media. Each strain was 10-fold serially diluted four times in DOB raf -ura media. Each suspension (20 $\mu \mathrm{l})$ was dropped onto DOB gal -ura plates and, then, was incubated for 2 days before colonies were counted or photographs were taken.

For yeast viability plating assays (Figs. 3B and 4), cultures were inoculated as described above. On the day of induction, cultures were resuspended to $\mathrm{OD}_{600}=0.4$ in fresh $\mathrm{DOB}$ raf - ura media and recovered for $2 \mathrm{~h}$ prior to induction with DOB gal -ura media. For induction, yeast cultures were normalized to $\mathrm{OD}_{600}=0.2$ in DOB gal -ura media. Timepoints were taken at $0,2,4$, and $6 \mathrm{~h}$ of induction with galactose by harvesting 200 $\mu \mathrm{l}$ from the growing culture. Each sample was 10-fold serially diluted four times in DOB raf -ura media. Each suspension $(20 \mu \mathrm{l})$ was dropped onto DOB glc -ura or EG plates and was then incubated for 2 days before colonies were counted or photographs were taken. Cultures harvested for the 0-h timepoint only had been exposed to raf media.

\section{Yeast microscopy analyses.}

For viability assays utilizing the incorporation of FUN-1 into cylindrical vacuolar structures, the Live/Dead yeast viability kit from Molecular Probes (Invitrogen) was used. Induction of protein expression was performed as described for the yeast viability plating assays. Alpha mating factor was added to a final concentration of $5 \mu \mathrm{g} / \mathrm{ml}$ to yeast expressing LacZ after 1 $\mathrm{h}$ of induction. Heat-treated LacZ-expressing cells were incubated at $55^{\circ} \mathrm{C}$ for $20 \mathrm{~min}$ after $3 \mathrm{~h}$ of induction to induce death. For all other strains, FUN-1 staining was carried out according to manufacturer's instructions after $3 \mathrm{~h}$ of induction. Briefly, yeast cells were washed in $2 \% \mathrm{D}-(+)$-glucose and $10 \mathrm{mM} \mathrm{Na}$ HEPES ( $\mathrm{pH}$ 7.2), were resuspended in the same buffer containing $10 \mu \mathrm{M}$ FUN-1 and $25 \mu \mathrm{M}$ calcafluor white, and were incubated in the dark at $30^{\circ} \mathrm{C}$ for $30 \mathrm{~min}$. Yeast cells were viewed immediately with an Olympus BX-50 microscope using a Chroma 11001v2 filter for red and green emission (Chroma Technology, Rockingham, VT, U.S.A.). Any cell containing red cylindrical structures within the vacuole was scored as viable.

Induction of protein expression for immunofluorescence assays was accomplished in the same manner as the FUN-1 viability assay, except that protein expression was induced for 1 $\mathrm{h}$ prior to fixation. Immunofluorescence methods were performed according to Pringle and coworkers (1991). Effector protein fusions with a V5-6His C-terminal tag were localized using anti-V5 monoclonal (Invitrogen) and anti-mouse fluorescein isothiocyanate (FITC) (Sigma-Aldrich, St. Louis) antibodies. For colocalization of effectors with the yeast mitochondrial porin protein, anti-porin monoclonal (Invitrogen) and antimouse tetramethyl rhodamine isothiocyanate (TRITC) antibodies (Jackson Immunoresearch, West Grove, PA, U.S.A.) were used in combination with anti-V5 FITC (Invitrogen). Observations were carried out using Chroma 41001 and 41017 filters for TRITC and FITC fluorescence, respectively. Images were ac- quired using a QImaging Retiga EXi cooled CCD camera and were processed via the Metamorph 6.1 software package (Molecular Devices, Downingtown, PA, U.S.A.). All observations were made using a $100 \times$ oil objective and $2 \times$ zoom.

\section{Plant transient expression assays.}

Agrobacterium tumefaciens GV3101 carrying the pLN462::hopAA1-1 truncations and $\beta$-glucuronidase plasmids were grown to saturation in LB. Cultures were washed twice with induction media $(10 \mathrm{mM} \mathrm{MgCl} 2,10 \mathrm{mM}$ morpholineethanesulfonic acid, $\mathrm{pH}$ 5.6, $400 \mu \mathrm{M}$ acetosyringone [Goodin et al. 2002]) and were resuspended to $\mathrm{OD}_{600}=0.3$. Cultures were incubated with shaking at room temperature for $2 \mathrm{~h}$ prior to inoculation. Agrobacterium suspensions were infiltrated into the apoplast of fully extended $N$. benthamiana, $N$. tabacum $\mathrm{cv}$. Xanthi, and tomato cv. Moneymaker leaves using a 1-ml blunt syringe. Plants were kept under laboratory conditions with a 12-h light cycle. Individual leaves were photographed 3 days postinfiltration.

\section{Protein extracts and immunoblotting.}

Yeast protein extractions were performed according to Kushnirov (2000). Briefly, protein expression in yeast was induced as described above. After $3 \mathrm{~h}$ of induction, a volume of culture equal to $\mathrm{OD}_{600}=2.5$ was harvested by centrifugation and was resuspended in $0.1 \mathrm{M} \mathrm{NaOH}$ to digest the cell walls. Cells were harvested again by centrifugation, were resuspended in sodium dodecyl sulfate (SDS) sample buffer, and were boiled to release the contents of the cells. Equal amounts of extract for each sample were separated by electrophoresis on a $12 \%$ SDS polyacrylamide gel. Proteins were transferred to Immobilon-P membranes (Millipore, Billerica, MA, U.S.A.) using a Semiphor semidry transfer apparatus (Hoefer, San Francisco, CA, U.S.A.). Membranes were probed with a primary, anti-V5 monoclonal antibody (Invitrogen) at a dilution of 1:1,000, followed by the secondary, anti-mouse antibody coupled to alkaline phosphatase (Sigma) at a dilution of 1:30,000.

Proteins were extracted from transiently transformed plant tissue $48 \mathrm{~h}$ postinfiltration. Two leaf disks were harvested using a $1-\mathrm{cm}$-diameter cork borer and were ground to a uniform consistency in $100 \mu \mathrm{l}$ of $8 \mathrm{M}$ urea. Cellular debris was removed by centrifugation, and the supernatant was mixed with SDS sample buffer. Equal amounts of extract for each sample were separated by electrophoresis and were transferred to a membrane as described above. Membranes were probed with a primary, anti-HA monoclonal antibody (Roche Applied Science, Indianapolis, IN, U.S.A.) at a dilution of 1:2,000, followed by a secondary, anti-rat antibody coupled to HRP (Roche Applied Science) at a dilution 1:10,000.

\section{ACKNOWLEDGMENTS}

We thank D. E. Fouts for pioneering observations of the deleterious effects of GAL1-promoter-dependent expression of the P. syringae pv. syringae 61 HopA1 protein, which encouraged the present work, A. T. Waickman for assisting with the subcloning of several effectors, K. Loeffler for photography, F. Vermeylen from the Cornell Statistical Consulting Unit for her help with the statistical analyses, and the National Science Foundation for support through grant DBI-0605059.

\section{LITERATURE CITED}

Abramovitch, R. B., Kim, Y. J., Chen, S. R., Dickman, M. B., and Martin, G. B. 2003. Pseudomonas type III effector AvrPtoB induces plant disease susceptibility by inhibition of host programmed cell death. EMBO (Eur. Mol. Biol. Organ.) J. 22:60-69.

Abramovitch, R. B., Janjusevic, R., Stebbins, C. E., and Martin, G. B. 2006. Type III effector AvrPtoB requires intrinsic E3 ubiquitin ligase 
activity to suppress plant cell death and immunity. Proc. Natl. Acad. Sci. U.S.A. 103:2851-2856.

Atkinson, M. M., and Baker, C. J. 1989. Role of the plasmalemma $\mathrm{H}^{+}$ Atpase in Pseudomonas syringae-induced $\mathrm{K}^{+} / \mathrm{H}^{+}$exchange in suspension-cultured tobacco cells. Plant Physiology 91:298-303.

Axtell, M. J., Chisholm, S. T., Dahlbeck, D., and Staskawicz, B. J. 2003. Genetic and molecular evidence that the Pseudomonas syringae type III effector protein AvrRpt2 is a cysteine protease. Mol. Microbiol. 49:1537-1546.

Badel, J. L., Charkowski, A. O., Deng, W.-L., and Collmer, A. 2002. A gene in the Pseudomonas syringae pv. tomato Hrp pathogenicity island conserved effector locus, hopPtoAl, contributes to efficient formation of bacterial colonies in planta and is duplicated elsewhere in the genome. Mol. Plant-Microbe Interact. 15:1014-1024.

Baker, C. J., Orlandi, E. W. and Deahl, K. L. 2000. Oxygen metabolism in plant/bacteria interactions: Characterization of the oxygen uptake response of plant suspension cells. Physiol. Mol. Plant Pathol. 57:159167.

Bretz, J. R., Mock, N. M., Charity, J. C., Zeyad, S., Baker, C. J., and Hutcheson, S. W. 2003. A translocated protein tyrosine phosphatase of Pseudomonas syringae pv. tomato DC3000 modulates plant defence response to infection. Mol. Microbiol. 49:389-400.

Chang, J. H., Urbach, J. M., Law, T. F., Arnold, L. W., Hu, A., Gombar, S., Grant, S. R., Ausubel, F. M., and Dangl, J. L. 2005. A high-throughput, near-saturating screen for type III effector genes from Pseudomonas syringae. Proc. Natl. Acad. Sci. U.S.A. 102:2549-54.

Chen, X. J., and Clark-Walker, G. D. 2000. The petite mutation in yeasts: 50 years on. Int. Rev. Cytol. 194:197-238.

Chivasa, S., Murphy, A. M., Naylor, M., and Carr, J. P. 1997. Salicylic acid interferes with tobacco mosaic virus replication via a novel salicylhydroxamic acid-sensitive mechanism. Plant Cell 9:547-557.

Coaker, G., Falick, A., and Staskawicz, B. 2005. Activation of a phytopathogenic bacterial effector protein by a eukaryotic cyclophilin. Science 308:548-550.

Cohn, J. R., and Martin, G. B. 2005. Pseudomonas syringae pv. tomato type III effectors AvrPto and AvrPtoB promote ethylene-dependent cell death in tomato. Plant J. 44:139-154.

DebRoy, S., Thilmony, R., Kwack, Y.-B., Nomura, K., and He, S. Y. 2004. A family of conserved bacterial effectors inhibits salicylic acid-mediated basal immunity and promotes disease necrosis in plants. Proc. Natl. Acad. Sci. U.S.A. 101:9927-9932.

Emanuelsson, O., Nielsen, H., Brunak, S., and von Heijne, G. 2000. Predicting subcellular localization of proteins based on their N-terminal amino acid sequence. J. Mol. Biol. 300:1005-1016.

Ephrussi, B., Hottinguer, H., and Chimenes, A. M. 1949a. Action De Lacriflavine Sur Les Levures .1. La Mutation Petite Colonie. Ann. I. Pasteur Paris 76:351-367.

Ephrussi, B., Hottinguer, H., and Tavlitzki, J. 1949b. Action De Lacriflavine Sur Les Levures .2. Etude Genetique Du Mutant Petite Colonie. Ann. I. Pasteur Paris 76:419-442.

Espinosa, A., Guo, M., Tam, V. C., Fu, Z. Q., and Alfano, J. R. 2003. The Pseudomonas syringae type III-secreted protein HopPtoD2 possesses protein tyrosine phosphatase activity and suppresses programmed cell death in plants. Mol. Microbiol. 49:377-387.

Ferreira, A. O., Meyers, C. R., Gordon, J. S., Martin, G. B., Vencato, M., Collmer, A., Wehling, M. D., Alfano, J. R., Moreno-Hagelsieb, G., Lamboy, W. F., DeClerk, G., Schneider, D. J., and Cartinhour, S. W. 2006. Whole-genome expression profiling defines the HrpL regulon of Pseudomonas syringae pv. tomato DC3000, allows de novo reconstruction of the Hrp cis element, and identified novel coregulated genes. Mol. Plant-Microbe Interact. 19:1167-1179.

Fu, Z. Q., Guo, M., Jeong, B. R., Tian, F., Elthon, T. E., Cerny, R. L., Staiger, D., and Alfano, J. R. 2007. A type III effector ADP-ribosylates RNA-binding proteins and quells plant immunity. Nature 447:284-288.

Gietz, D., St. Jean, A., Woods, R. A., and Schiestl, R. H. 1992. Improved method for high efficiency transformation of intact yeast cells. Nucleic Acids Res. 20:1425.

Goodin, M. M., Dietzgen, R. G., Schichnes, D., Ruzin, S., and Jackson, A. O. 2002. pGD vectors: Versatile tools for the expression of green and red fluorescent protein fusions in agroinfiltrated plant leaves. Plant J. 31:375-383

Guttman, D. S., Vinatzer, B. A., Sarkar, S. F., Ranall, M. V., Kettler, G., and Greenberg, J. T. 2002. A functional screen for the type III (Hrp) secretome of the plant pathogen Pseudomonas syringae. Science 295:1722-1726.

Hann, D. R., and Rathjen, J. P. 2007. Early events in the pathogenicity of Pseudomonas syringae on Nicotiana benthamiana. Plant J. 49:607618.

Hauck, P., Thilmony, R., and He, S. Y. 2003. A Pseudomonas syringae type III effector suppresses cell wall-based extracellular defense in sus- ceptible Arabidopsis plants. Proc. Natl. Acad. Sci. U.S.A. 100:85778582

He, P., Shan, L., Lin, N. C., Martin, G. B., Kemmerling, B., Nurnberger, T., and Sheen, J. 2006. Specific bacterial suppressors of MAMP signaling upstream of MAPKKK in Arabidopsis innate immunity. Cell 125:563-575

Hoeberichts, F. A., and Woltering, E. J. 2003. Multiple mediators of plant programmed cell death: interplay of conserved cell death mechanisms and plant-specific regulators. Bioessays 25:47-57.

Huh, W. K., Falvo, J. V., Gerke, L. C., Carroll, A. S., Howson, R. W., Weissman, J. S., and O'Shea, E. K. 2003. Global analysis of protein localization in budding yeast. Nature 425:686-691.

Jamir, Y., Guo, M., Oh, H. S., Petnicki-Ocwieja, T., Chen, S., Tang, X., Dickman, M. B., Collmer, A., and Alfano, J. R. 2004. Identification of Pseudomonas syringae type III effectors that can suppress programmed cell death in plants and yeast. Plant J. 37:554-565.

Jelenska, J., Yao, N., Vinatzer, B. A., Wright, C. M., Brodsky, J. L., and Greenberg, J. T. 2007. A J domain virulence effector of Pseudomonas syringae remodels host chloroplasts and suppresses defenses. Curr. Biol. 17:499-508.

Jimenez, J., Longo, E., and Benitez, T. 1988. Induction of petite yeast mutants by membrane-active agents. Appl. Environ. Microbiol. 54:31263132 .

Kenny, B., and Jepson, M. 2000. Targeting of an enteropathogenic Escherichia coli (EPEC) effector protein to host mitochondria. Cell. Microbiol. 2:579-590.

Kramer, R. W., Slagowski, N. L., Eze, N. A., Giddings, K. S., Morrison, M. F., Siggers, K. A., Starnbach, M. N., and Lesser, C. F. 2007. Yeast functional genomic screens lead to identification of a role for a bacterial effector in innate immunity regulation. PLoS Pathog 3 (2):e21.

Kushnirov, V. V. 2000. Rapid and reliable protein extraction from yeast. Yeast 16:857-860.

Layton, A. N., Brown, P. J., and Galyov, E. E. 2005. The Salmonella translocated effector SopA is targeted to the mitochondria of infected cells. J. Bacteriol. 187:3565-71.

Lesser, C. F., and Miller, S. I. 2001. Expression of microbial virulence proteins in Saccharomyces cerevisiae models mammalian infection. EMBO (Eur. Mol. Biol. Organ.) J. 20:1840-1849.

Li, X., Lin, H., Zhang, W., Zou, Y., Zhang, J., Tang, X., and Zhou, J. M. 2005. Flagellin induces innate immunity in nonhost interactions that is suppressed by Pseudomonas syringae effectors. Proc. Natl. Acad. Sci. U.S.A. 102:12990-12995.

Lindeberg, M., Cartinhour, S., Meyers, C. R., Schechter, L. M., Schneider, D. J., and Collmer, A. 2006. Closing the circle on the discovery of genes encoding Hrp regulon members and type III secretion system effectors in the genomes of three model Pseudomonas syringae strains. Mol. Plant-Microbe Interact. 19:1151-1158.

Liu, H., Krizek, J., and Bretscher, A. 1992. Construction of a GAL1-regulated yeast cDNA expression library and its application to the identification of genes whose overexpression causes lethality in yeast. Genetics 132:665-673

Lopez-Solanilla, E., Bronstein, P. A., Schneider, A. R., and Collmer, A. 2004. HopPtoN is a Pseudomonas syringae Hrp (type III secretion system) cysteine protease effector that suppresses pathogen-induced necrosis associated with both compatible and incompatible plant interactions. Mol. Microbiol. 54:353-365.

Ma, C., Wickham, M. E., Guttman, J. A., Deng, W., Walker, J., Madsen, K. L., Jacobson, K., Vogl, W. A., Finlay, B. B., and Vallance, B. A. 2006a. Citrobacter rodentium infection causes both mitochondrial dysfunction and intestinal epithelial barrier disruption in vivo: Role of mitochondrial associated protein (Map). Cell. Microbiol. 8:1669-1686.

Ma, W., Dong, F. F., Stavrinides, J., and Guttman, D. S. 2006b. Type III effector diversification via both pathoadaptation and horizontal transfer in response to a coevolutionary arms race. PLoS Genet 2 (12):e209.

Madeo, F., Herker, E., Maldener, C., Wissing, S., Lachelt, S., Herlan, M., Fehr, M., Lauber, K., Sigrist, S. J., Wesselborg, S., and Frohlich, K. U. 2002. A caspase-related protease regulates apoptosis in yeast. Mol. Cell. 9:911-917.

Madeo, F., Herker, E., Wissing, S., Jungwirth, H., Eisenberg, T., and Frohlich, K. U. 2004. Apoptosis in yeast. Curr. Opin. Microbiol. 7:655660.

Millard, P. J., Roth, B. L., Thi, H. P., Yue, S. T., and Haugland, R. P. 1997. Development of the FUN-1 family of fluorescent probes for vacuole labeling and viability testing of yeasts. Appl. Environ. Microbiol 63:2897-2905.

Nagai, T., Abe, A., and Sasakawa, C. 2005. Targeting of enteropathogenic Escherichia coli EspF to host mitochondria is essential for bacterial pathogenesis: critical role of the 16th leucine residue in EspF. J. Biol. Chem. 280:2998-3011.

Nielsen, H., Engelbrecht, J., Brunak, S., and von Heijne, G. 1997. Identifi- 
cation of prokaryotic and eukaryotic signal peptides and prediction of their cleavage sites. Protein Eng. 10:1-6.

Nougayrede, J. P., and Donnenberg, M. S. 2004. Enteropathogenic Escherichia coli $\mathrm{EspF}$ is targeted to mitochondria and is required to initiate the mitochondrial death pathway. Cell Microbiol. 6:1097-1111.

Oh, H. S., and Collmer, A. 2005. Basal resistance against bacteria in Nicotiana benthamiana leaves is accompanied by reduced vascular staining and suppressed by multiple Pseudomonas syringae type III secretion system effector proteins. Plant J. 44:348-359.

Orth, K. 2002. Function of the Yersinia effector YopJ. Curr. Opin. Microbiol. 5:38-43.

Pringle, J. R., Adams, A. E., Drubin, D. G., and Haarer, B. K. 1991. Immunofluorescence methods for yeast. Methods Enzymol. 194:565-602.

Quitard, S., Dean, P., Maresca, M., and Kenny, B. 2006. The enteropathogenic Escherichia coli EspF effector molecule inhibits PI-3 kinasemediated uptake independently of mitochondrial targeting. Cell Microbiol. 8:972-981.

Rhoads, D. M., and McIntosh, L. 1993. The salicylic acid-inducible alternative oxidase gene aox 1 and genes encoding pathogenesis-related proteins share regions of sequence similarity in their promoters. Plant Mol. Biol. 21:615-624.

Rohmer, L., Guttman, D. S., and Dangl, J. L. 2004. Diverse evolutionary mechanisms shape the type III effector virulence factor repertoire in the plant pathogen Pseudomonas syringae. Genetics 167:1341-1360.

Rosebrock, T. R., Zeng, L., Brady, J. J., Abramovitch, R. B., Xiao, F., and Martin, G. B. 2007. A bacterial E3 ubiquitin ligase targets a host protein kinase to disrupt plant immunity. Nature 448:370-374.

Sambrook, J., Fritsch, E. F., and Maniatis, T. 1989. Molecular Cloning: A Laboratory Manual. 2nd ed. Cold Spring Harbor Laboratory Press. Cold Spring Harbor, NY, U.S.A.

Sarkar, S. F., Gordon, J. S., Martin, G. B., and Guttman, D. S. 2006. Comparative genomics of host-specific virulence in Pseudomonas syringae. Genetics 174:1041-1056.

Schechter, L. M., Vencato, M., Jordan, K. L., Schneider, S. E., Schneider, D. J., and Collmer, A. 2006. Multiple approaches to a complete inventory of Pseudomonas syringae pv. tomato DC3000 type III secretion system effector proteins. Mol. Plant-Microbe Interact. 19:1180-1192.

Shao, F., Merritt, P. M., Bao, Z., Innes, R. W., and Dixon, J. E. 2002. A Yersinia effector and a Pseudomonas avirulence protein define a family of cysteine proteases functioning in bacterial pathogenesis. Cell 109:575-588
Sherman, F. 2002. Getting started with yeast. Methods Enzymol. 350:341.

Simons, B. H., Millenaar, F. F., Mulder, L., Van Loon, L. C., and Lambers, H. 1999. Enhanced expression and activation of the alternative oxidase during infection of Arabidopsis with Pseudomonas syringae pv. tomato. Plant. Physiol. 120:529-538.

Valdivia, R. H. 2004. Modeling the function of bacterial virulence factors in Saccharomyces cerevisiae. Eukaryot. Cell 3:827-834.

Van der Biezen, E. A., and Jones, J. D. 1998. Plant disease-resistance proteins and the gene-for-gene concept. Trends Biochem. Sci. 23:454-456.

Vinatzer, B. A., Jelenska, J., and Greenberg, J. T. 2005. Bioinformatics correctly identifies many type III secretion substrates in the plant pathogen Pseudomonas syringae and the biocontrol isolate $P$. fluorescens SBW25. Mol. Plant-Microbe Interact. 18:877-888.

Vinatzer, B. A., Teitzel, G. M., Lee, M. W., Jelenska, J., Hotton, S., Fairfax, K., Jenrette, J., and Greenberg, J. T. 2006. The type III effector repertoire of Pseudomonas syringae pv. syringae $\mathrm{B} 728 \mathrm{a}$ and its role in survival and disease on host and non-host plants. Mol. Microbiol. 62:26-44.

Von Pawel-Rammingen, U., Telepnev, M. V., Schmidt, G., Aktories, K., Wolf-Watz, H., and Rosqvist, R. 2000. GAP activity of the Yersinia YopE cytotoxin specifically targets the Rho pathway: A mechanism for disruption of actin microfilament structure. Mol. Microbiol. 36:737748.

Wei, C. F., Kvitko, B. H., Shimizu, R., Crabill, E., Alfano, J. R., Lin, N. C., Martin, G. B., Huang, H. C., and Collmer, A. 2007. A Pseudomonas syringae pv. tomato DC3000 mutant lacking the type III effector HopQ1-1 is able to cause disease in the model plant Nicotiana benthamiana. Plant J. 51:32-46.

Yoon, S., Liu, Z., Eyobo, Y., and Orth, K. 2003. Yersinia effector YopJ inhibits yeast MAPK signaling pathways by an evolutionarily conserved mechanism. J. Biol. Chem. 278:2131-2135.

Zhang, J., Shao, F., Li, Y., Cui, H., Chen, L., Li, H., Zou, Y., Long, C., Lan, L., Chai, J., Chen, S., Tang, X., and Zhou, J. M. 2007. A Pseudomonas syringae effector inactivates MAPKs to suppress PAMP-induced immunity in plants. Cell Host Microbe 1:175-185.

\section{AUTHOR-RECOMMENDED INTERNET RESOURCE}

University of California Yeast GFP Fusion Localization Database: yeastgfp.ucsf.edu 